
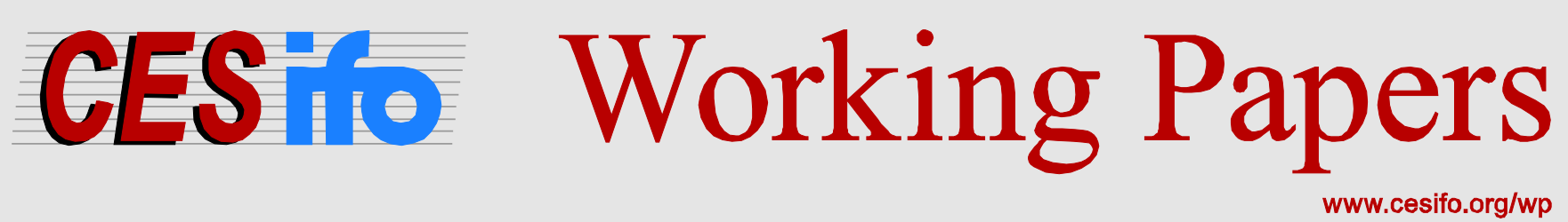

\title{
Imperfect Financial Markets as a Commitment Device for the Government
}

\author{
Jenny Simon \\ CESIFO WORKING PAPER NO. 4902 \\ CATEGORY 1: PUBLIC FINANCE \\ JULY 2014 \\ Presented at CESifo Area Conference on Public Sector Economics, April 2013 \\ An electronic version of the paper may be downloaded \\ - from the SSRN website: \\ - from the RePEc website: \\ WWW.SSRN.com \\ www.RePEc.org \\ - from the CESifo website: \\ www.CESifo-group.org/wp
}




\title{
Imperfect Financial Markets as a Commitment Device for the Government
}

\begin{abstract}
When the government lacks the ability to commit to a tax policy over time, agents' involvement in imperfect financial markets can be welfare improving. Agents borrow against their promised income in markets that are incomplete in the sense that claims cannot be resold without loss. Taking these contractual positions into account thus changes the government's ex-post incentives to renege on the promised tax schedule. Any increase in redistribution expost would lead to some agents not being able to fulfill their financial liabilities. The impending individual "default losses" add up to an effective commitment device for the government. Even a small market imperfection yields limited commitment, which leads to optimal partial pooling in the tax schedule.
\end{abstract}

JEL-Code: E610, H210, D820.

Keywords: limited commitment, commitment device, financial markets, incomplete markets, revelation theorem, redistribution Mirrlees.

\author{
Jenny Simon \\ Stockholm Institute of Transition Economics \\ Stockholm School of Economics \\ Sveavägen 65, P.O.Box 6501 \\ Sweden - 11383 Stockholm \\ jenny.simon@hhs.se
}

June 2014

I would like to thank Daron Acemoglu and Ivan Werning for their guidance and support. I also thank Arpad Abraham, Maya Eden, Mikhail Golosov, Christian Hellwig, Martin Hellwig, Nathan Hendren, Luigi Iovino, Kai Konrad, Ben Lockwood, James Poterba, Florian Scheuer, Justin Valasek, and John Weymark as well as seminar participants at MIT, EUI, Cambridge University, Toulouse School of Economics, and IIES, and conference participants at the SED and EEA meetings 2011, the AEA meetings 2012, the Nashville Taxation Theory Conference 2012, and the CESifo Public Sector Economics Conference 2013 for helpful comments. I gratefully acknowledge generous financial support from the Peters-Beer-Stiftung. All errors are my own. 


\section{Introduction}

When agents are privately informed about their ability to generate income, the government's capacity to implement social redistribution depends crucially on its power to commit to future policy. ${ }^{2}$ Yet, most of what we know about optimal income taxes in private information settings has been derived under the assumption of full commitment ${ }^{3}$ and real world tax schedules suggest that governments can indeed commit at least partially. There is, however, little reason to believe that governments possess some exogenous commitment device. Instead, commitment must stem from the environment the government operates in. This paper demonstrates that agents' involvement in financial markets can alleviate the government's commitment problem and so facilitate social redistribution. Importantly, markets have this favorable effect only when they are imperfect.

In market economies, individuals do not typically constrain their consumption to equal net-of-tax income every period. Instead, they use financial markets to allocate their resources over time. For instance, a mortgage contract enables agents to live in a house that reflects their life-time income rather than in a rental unit that reflects their present disposable income every period. The financial markets that people use in reality, however, are typically imperfect in the sense that adjustments to contracts are costly. If at any point in time an agent cannot afford his mortgage payments anymore, he needs to refinance, sell or even default - none of which are costless options. Consequently, by using markets, agents enter individual commitments. Chetty and Szeidl (2007) report that nearly $65 \%$ of the average US household's budget is allocated to consumption commitments that cannot be adjusted costlessly.

I show that optimal redistributive policy takes agents' involvement in such financial markets into account. When re-optimizing, the benevolent government considers agents' contractual positions. If an agent ends up with less net income than promised, he will have to adjust his consumption plan downward and possibly adjust his financial contracts. The costs of such adjustment (or "default") can deter the government from reneging on past promises. I show that even though these consumption commitments are enforceable only at the individual level, the imminent default costs for each individual agent add up to an effective commitment device for the government.

Theoretically, this description of market imperfection maps into the concept of mar-

\footnotetext{
$2 \overline{\text { Since the seminal contribution by Mirrlees }}$ (1971), it is well understood that the income tax schedule needs to provide incentives for agents to reveal their types (see also Dasgupta et al. (1979), Harris and Townsend (1981), and Holmström and Myerson (1983) for other early contributions.). After this information has been revealed, however, a benevolent government is tempted to implement extreme levels of redistribution. Since agents anticipate such deviations, a lack of commitment to honor promises in the future is generally expected to lead to extremely inefficient outcomes. This has been demonstrated first by Roberts (1984) and more recently extended to a dynamic setting by Golosov et al. (2006)

${ }^{3}$ See Golosov et al. (2006) for an overview. There has only recently been some interest in characterizing optimal Mirrleesian taxes in setups without commitment. See for example Brett and Weymark (2011) and Berliant and Ledyard (2005).
} 
ket incompleteness in the classical sense: There are no complete resale markets for financial claims at every point in time. To model varying degrees of market incompleteness, I assume that complete spot markets exist, but that accessing them is costly. As the main result, I derive a condition that links the degree of market incompleteness (i.e. the access or "default" cost) to the level of incentive payments the government is effectively able to commit to. Intuitively, this condition equalizes the marginal benefit from additional redistribution toward the low end of the type distribution to the marginal cost due to default. The larger the default costs are, the more separation and so the more incentive provision is possible, since agents correctly anticipate that the government will not find it profitable to renege on its promise ex-post. This new degree of freedom for government policy always weakly improves welfare. I characterize conditions on the level of inequality under which the improvement is strict.

Even though theoretically possible, this mechanism arguably may not be strong enough in reality to provide full commitment. The main result of the paper shows, however, that even a small market imperfection still leads to a limited degree of effective commitment. Moreover, I show that whenever ex-ante inequality exceeds a certain level, the government uses its limited commitment ability optimally by collecting only a limited amount of information. The optimal tax schedule partially pools some agents of the type distribution. In other words, the degree of market imperfection is endogenously linked to the degree to which a government can commit to a tax schedule over time and determines how much information is optimally used to set personal income taxes.

In the course of deriving these results, the paper also makes a theoretical contribution to the literature on mechanism design under limited commitment. Since I study a finite horizon model where the government is not able to commit, the Revelation Principle does not apply. Instead, I prove a Truth-telling theorem that still allows attention to be restricted to direct albeit not fully revealing mechanisms. The separation of truth-telling from full revelation allows me to significantly restrict the set of mechanisms to search over for the optimum. This class of mechanisms still provides incentives for agents to tell the truth directly to the mechanism designer, yet allows for truthful messages to reveal only partial information. With this result, I show that finding the best implementable mechanism can be divided into two problems: The determination of how much information should be revealed (i.e. which types should pool) and the search for the optimal tax-transfer scheme based on that limited information. This structure enables me to explicitly link limited commitment to limited information revelation and forms of partial pooling.

\section{Related Literature}

The question of what enables governments to commit not to expropriate agents in the economy has of course received attention in the literature. So far, the focus has been on political structures and reputational effects in repeated games. Acemoglu et al. $(2008,2010)$ consider self-interested politicians who cannot commit not to misuse information and can appropriate resources for their own benefit. They show 
that in an infinite horizon setup such governments can effectively commit on the equilibrium path, essentially because they want to maintain their rents agreed upon in the social contract. Such an equilibrium can only exist when it is supported by the threat of agents reverting to the worst outcome after a government deviates from promised policy (either by not producing anything, or by replacing the government). In that sense, their findings are parallel to reputation mechanisms - a channel completely abstracted from in this paper. The paper presented here contributes another potential channel by which characteristics of the economy can lead at least to limited effective commitment: agents trading in imperfect markets.

The effect of agents being able to use financial markets to allocate their resources on optimal taxation has also received attention. Many authors have considered environments in which agents cannot only contract with a principal, but also in anonymous outside markets that make it harder to extract information from the agents truthfully. See for example Hammond (1987) for a general treatment or Golosov and Tsyvinsky (2007) for a more recent example from the dynamic public finance literature. The general conclusion is that when the government has an exogenous commitment device, letting agents use markets to allocate resources decreases the set of policy instruments available to the government and so hinders redistribution. The main argument of the paper presented here is that this conclusion does not hold when the government has no exogenous commitment device.

Bisin and Rampini (2006) study a no-commitment setup similar to the one considered here, but focus on the allocative role of anonymous markets. They find that allowing agents access to such markets is beneficial in a world where the government has no commitment, because it allows them to allocate resources over time without revealing any information, thereby increasing efficiency. However, the government's commitment problem is unchanged, no social redistribution can be implemented. In contrast, I analyze a market that does not act as a "tax haven". The crucial characteristic of private contracts I consider is that they constitute consumption commitments that cannot costlessly be changed. This increases the government's commitment power, enabling it to implement some social insurance.

The theoretical contribution of this paper relates to a growing body of literature on mechanism design and lack of commitment. Bester and Strausz (2001) show that a version of the Revelation Principle applies in situations when the principal without commitment faces only one agent. Their argument, however, does not extend to the multi-agent case (Bester and Strausz (2000)). In an infinite horizon setup with a continuum of agents, Acemoglu et al. (2006) show that the Revelation Principle holds on the equilibrium path, supported by the threat of agents reverting to not revealing any information after a deviation by the government. This paper instead focuses on a finite horizon game, where truthful revelation cannot be supported by such a threat. In a setup closely related to the on presented here, Bester and Strausz (2007) investigate noisy communication, but consider a finite number of types. In the model presented here, the principal facing a continuum of types does not choose to introduce noise. 
The paper is organized as follows: Section 2 sets up the economy and describes how agents can trade in imperfect markets. Section 3 formally defines strategies of agents and the government as well as the timing of the policy game and the equilibrium. In section 4 , I derive the theoretical results that allow me to analyze this game as a mechanism design problem. Section 5 provides relevant benchmark allocations before section 6 presents the main result of the paper - how agents' involvement in imperfect markets can serve as a commitment device for the government. Conditions under which this mechanism leads to a strict welfare improvement as well as conditions under which the optimal tax schedule will involve partial pooling are derived in section 7 . Finally, section 8 discusses the generality of the results when relaxing some key modelling assumptions and concludes.

\section{$2 \quad$ A stylized model}

In this section, I introduce a very stylized model economy. In particular the assumptions numbered $A 1$ through $A 3$ may seem to render the model extremely far from any real world application. I choose this setup to depict the commitment problem of the government and its interaction with a market imperfection in the cleanest way possible and will discuss the generality of the results with respect to these assumptions in section 8.

\subsection{Endowment economy}

The model economy lasts for 2 periods (indexed $t=1,2$ ) and is inhabited by a continuum of agents of unit mass. Agents derive utility from a single consumption good according to

$$
U=u\left(c_{1}\right)+\beta u\left(c_{2}\right),
$$

where $\beta \in(0,1]$ is the time discount factor. Utility is time-separable, and the per period utility function $u(\cdot)$ is strictly increasing, concave, and $\lim _{c \rightarrow 0} u^{\prime}(c)=\infty$. Moreover, I assume that $u$ displays constant elasticity of intertemporal substitution.

Agents receive heterogeneous income $y_{t}(\theta)$ at the beginning of each period. Income types $\theta$ are perfectly persistent over time and are private information. Across the population, $\theta$ is continuously distributed over a support $\Theta=[\underline{\theta}, \bar{\theta}] . F(\theta)$ denotes its cdf, and is assumed to be twice continuously differentiable. Apart from income heterogeneity, agents are identical.

To illustrate the main mechanism in the simplest possible way, I assume that

(A1) $y_{t}(\theta)=t \theta \quad \forall t, \theta$ and $\beta=1$.

In this specification of the model, all agents have an increasing income stream over their lifetime. Lower type agents receive smaller endowments than higher types at all times. Moreover, agents do not discount the future. The no discounting assumption is for notational simplicity only and without loss of generality; the results persist as 
long as agents do not completely disregard the future, i.e. as long as they have a discount factor strictly greater than zero. ${ }^{4}$

Suppose there exists a technology to costlessly transfer resources over time and consider the problem of a benevolent social planner with a utilitarian objective and equal Pareto weights on all agents. He chooses an allocation $\left\{c_{t}(\theta)\right\}_{t, \Theta}$ that assigns a consumption level to each type $\theta \in \Theta$, for each period $t=1,2$.

$$
\begin{aligned}
& \max _{\left\{c_{t}(\theta)\right\}_{t, \Theta}} \int_{\Theta}\left(u\left(c_{1}(\theta)\right)+u\left(c_{2}(\theta)\right)\right) d F(\theta) \\
& \text { s.t. } \int_{\Theta}\left(c_{1}(\theta)+c_{2}(\theta)\right) d F(\theta) \leq \int_{\Theta}\left(y_{1}(\theta)+y_{2}(\theta)\right) d F(\theta) .
\end{aligned}
$$

Since he does not face any information constraints, the benevolent planner implements full redistribution across the population, as well as complete consumption smoothing for each individual agent, i.e. at the first-best $c_{1}(\theta)=c_{2}(\theta)=c$ for all types $\theta$.

\subsection{Government with information constraints and lack of commitment}

Suppose that instead of an omniscient planner a benevolent government with the same utilitarian objective and no additional revenue requirements is in charge. Like the planner, the government has access to a costless transfer technology:

(A2) The government can save and borrow at $R=1$ from exogenous funds. It faces the natural borrowing constraint.

In other words, the government can always commit to repaying its debt to the exogenous fund. However, this does not help with the commitment problem with respect to the agents, which is the focus of this paper.

To implement the desired allocation, the government would like to institute schedules of type specific taxes and transfers. In doing so, however, it faces several difficulties: First, it cannot observe an agent's type. When conditioning the allocation on income types, it must rely on information provided directly by the agents or indirectly through their actions in the economy. Second, the government is not able to commit to a second period transfer schedule ex-ante. At the beginning of the second period, possibly contrary to earlier promises, the government might implement a tax schedule based on information it has learned about the agents in the meantime. This lack of commitment with respect to the tax schedule is known to all players in the economy.

\footnotetext{
${ }^{4}$ Of course, the exact allocation would depend on the discount factor, but the qualitative characteristics of the equilibrium derived in the next sections do not.
} 


\subsection{Agents trading in imperfect markets}

Agents in this economy are also able to allocate their own resources over time using the same exogenous funds. In period 1, they may sign contracts with an exogenous lender

$$
x=\left(b_{1}, b_{2}, h_{1}, h_{2}\right) \quad \text { with } h_{t}, b_{t} \geq 0,
$$

that specify a consumption stream of $h_{t}$ units in period $t$ for payments of $b_{t}$ by the agent. This format of financial contracts is very general, in particular it allows for agents to simultaneously make and receive a payment. Accordingly, I refer to contracts with $h_{2}>0$ as gross contracts $^{5}$. Agents face the same terms as the government:

(A3) Agents can save and borrow at $R=1$ from exogenous funds. They face natural, type-dependent borrowing constraints. ${ }^{6}$

These contracts are publicly observable, and individually enforceable, i.e. the exogenous lender can enforce the contracted payment $b_{t}$ only from the individual agent, not from the government. ${ }^{7}$

For future reference, let $X$ denote the set of all contracts that are ex-ante feasible. For notational consistency, let $X$ include the element $x_{0}=(0,0,0,0)$ which symbolizes that the agent has not signed a contract.

The financial market agents may trade in is imperfect. While contracts can be type-specific, they cannot be conditioned on anything else. Instead:

(A4) There exist resale markets in period $t=2$, where claims $h_{2}$ can be sold for face value. However, to access these spot markets, the agent needs to pay an access fee $D \geq 0$.

This cost $D$ is a deadweight loss that arises from having to change a contract. It essentially renders agents' financial contracts to be individual consumption commitments that cannot costlessly be changed. $D$ can be thought of as a measure of market incompleteness. If $D=0$, we recover complete markets.

\footnotetext{
${ }_{5}^{\mathrm{A}}$ mortgage is an example for a gross contract: The agent makes mortgage payments to the bank and receives a transfer in form of the house (or increased ownership) in return every period.

${ }^{6}$ In other words, agents use a market that is perfectly competitive ex-ante. Lenders can verify income types at no cost. However, they do not sell or use this information for any purpose other than tailoring type specific financial contracts to their clients. This assumption clearly restricts the model's fit with reality. It considerably simplifies the analysis in that it avoids the added complication of any adverse selection problems in the financial market. I make this assumption to focus on the commitment mechanism for the government only. An alternative model without this assumption is provided in section 8. All qualitative results hold there, too.

${ }^{7}$ The enforceability of contracts is never revoked. However, this does not mean that lenders can force the government to bail out an agent. They only possess enforcement power over the party they directly contracted with, i.e. the individual agent. The government has the first take on agents' income, only thereafter can lenders enforce the repayment of outstanding debt from the individual agent. However, since agents cannot consume before repaying all their debt, the benevolent government will take the agents' contractual position into account.
} 
To gain some intuition for the market imperfection $D$ is supposed to capture, consider a mortgage contract. Since agents simultaneously repay their mortgage and live in their house, this would be considered a gross contract. If at any point in time an agent ends up with less net income than he expected, he might have to refinance his mortgage or even default. This process is never without loss: A foreclosed house often does not sell for the same amount as it was worth to the original owner. Administration of defaults or refinancing is costly. But also non-pecuniary losses may occur, when agents have to move out of the house they grew attached to. Instead, if markets were complete, the agent would simply sell partial user rights to the house and continue living in it for a fraction of his life time, so that he could avoid the above mentioned costs. Taking all these into account, the access cost $D$ should be thought of as the total cost of renegotiating a long-term contract in the financial market.

\section{Strategies and equilibrium}

The government's lack of the ability to commit to a tax schedule over time turns the setup into a policy game between agents, choosing which information to report to the government and which contract to sign in the financial market, and the government, choosing the transfers to implement in each period. The focus of this paper is to characterize the equilibrium of this game that corresponds to the best implementable mechanism, i.e. the mechanism (or tax schedule) that maximizes ex-ante welfare in the economy. In this section, I formally define the game, the players' strategies and the equilibrium.

Denote with $Z$ a general message space, and by $z$ a generic element of $Z$. The message space includes messages about an agent's type, but may also include other elements. A tax schedule, or more formally a mechanism $\tau=\left(\tau_{1}, \tau_{2}\right)$, consists of two mappings $\tau_{t}: Z \times X \mapsto \mathbb{R}$. Each of these mappings specifies a tax or transfer payment (for period 1 and 2 respectively) for an agent who reported message $z$ and signed contract $x$. Let $T$ denote the set of mechanisms that are ex-ante resource feasibile. Moreover, let $T^{\prime}$ denote the set of feasible mappings $\tau_{2}$, that are also exinterim feasible (i.e. given $\tau_{1}$ ).

To analyze this game formally, consider the following timing of action:

$\mathrm{t}=1 \quad$ a) The government announces a mechanism $\tilde{\tau}=\left(\tilde{\tau}_{1}, \tilde{\tau}_{2}\right), \tilde{\tau} \in T$.

Agents receive their first endowment and send a message $z \in Z$.

Agents sign a contract $x \in X$ in the financial market.

b) $\tilde{\tau}_{1}$ is implemented according to the announcement $\tilde{\tau}$. Payments $\left(b_{1}, h_{1}\right)$ of all financial contracts are made.

Agents consume.

$\mathrm{t}=2$ a) The government chooses a new tax schedule $\tilde{\tau}_{2}^{\prime} \in T^{\prime}$ for period 2, which may differ from the previous announcement $\tilde{\tau}_{2}$. 
Agents receive their second endowment.

Agents and banks (may) renegotiate their private contracts to $x^{\prime}$.

b) $\tilde{\tau}_{2}^{\prime}$ is implemented.

Payments $\left(b_{2}^{\prime}, h_{2}^{\prime}\right)$ of all financial contracts are made.

Agents consume.

Each period begins with an active stage where the government announces a tax schedule and agents may reveal information and sign or modify a contract in the financial market ${ }^{8}$. It is followed by an implementation stage that is automatic, no further actions can be taken by any player of the game. This setup emphasizes the intertemporal commitment problem of the government: While it can commit to a tax schedule within a period (i.e. the implementation in stage b) follows automatically), it is not able to commit to a mechanism across periods. After agents have revealed information in period 1 , the government can renege on the promised tax schedule $\tilde{\tau}$ and use the information acquired.

In summary, the government's action $\gamma=\left(\tilde{\tau}, \tilde{\tau}_{2}^{\prime}\right)$ consists of two elements: the initial announcement of a mechanism (or tax schedule) $\tilde{\tau}$, and the (possibly amended) tax schedule $\tilde{\tau}_{2}^{\prime}$ that is actually implemented in period 2 . For notational simplicity, a tax schedule that is not changed will still be called $\tilde{\tau}_{2}^{\prime}$, so that in case the government does not choose to deviate from its promise, $\tilde{\tau}_{2}^{\prime}=\tilde{\tau}_{2}$. Let $G$ denote the set of $\gamma^{\prime}$ s.

The action of an agent of type $\theta$, denoted $\sigma_{\theta}=\left(z, x, x^{\prime}\right)$, consists of three elements: First, it specifies the message $z \in Z$ sent to the government. Second, it specifies the contract $x$ the agent signs with a lender in period 1 . Third, it includes $x^{\prime}$, which summarizes the agent's contractual position after a possible access to the resale market in period 2. Again, a contract that is not actually changed will still be called $x^{\prime}$, so that in case an agent does not renegotiate, his contract will be $x^{\prime}=x$. The renegotiation cost $D$ that stands for market imperfection is only incurred whenever $x^{\prime} \neq x$. In that sense, $x$ and $x^{\prime}$ summarize the contractual position of an agent in period 1 and period 2 respectively. Let $X^{\prime}$ denote the set of contracts that are feasible at the point of possible renegotiation. Let $\Sigma_{\theta}$ denote the set of possible actions for an agent of type $\theta$ and $\Sigma$ the collection of these sets for all possible types, $\Sigma=\bigcap_{\Theta} \Sigma_{\theta}$. Before the revelation of his type, the strategy $\sigma$ of an agent thus is a mapping $\sigma: \Theta \times G \mapsto \Sigma$.

I denote with $z(\sigma(\theta, \gamma))$ the message that results from strategy $\sigma$ for an agent with realized type $\theta$ and for the government action $\gamma$.

\section{Definition 1 (Truth-telling)}

A strategy $\sigma^{*}$ is called TRUTHFUL if

$$
z\left(\sigma^{*}(\theta, \gamma)\right)=z[\theta] \quad \forall \theta \in \Theta, \gamma \in G
$$

where the notation $z[\theta]$ means that the information revealed by the message is true.

\footnotetext{
${ }^{8}$ For the sake of formal equilibrium analysis, one may think of the actions in stage a) of each period to take place simultaneously.
} 
An agent playing a truthful strategy will not lie about his type. Note, however, that a truthful strategy does not necessarily reveal the exact type of an agent. One might think of an agent revealing that he is "at least type $\theta$ " or his income falls into a certain interval. The continuum of agents playing such a strategy could for example result in partial pooling around certain cutoff types. One particular truthful strategy does reveal the exact type, and is defined as follows:

\section{Definition 2 (Truthful revelation)}

A strategy $\sigma^{R}$ is called TRUTHFULLY REVEALING if it is truthful and there exists a one-to-one mapping from the message to the exact type:

$$
z[\theta] \longmapsto \theta .
$$

If an agent plays a truthfully revealing strategy, the government will be able to infer his exact income type from the message sent.

Lastly, let $\boldsymbol{\sigma}$ denote a strategy profile for all individuals, and $\boldsymbol{\Sigma}$ the set of all such strategy profiles. Analogously, $\boldsymbol{\sigma}^{*}$ and $\boldsymbol{\sigma}^{R}$ denote strategy profiles where all agents play truth-telling or truthfully revealing strategies respectively. Then the government's strategy is defined as a mapping $\Gamma: \Sigma \mapsto G$

\section{Definition 3 (Equilibrium)}

A (perfect Bayesian) equilibrium in the game between agents and the government is given by a strategy $\Gamma^{e}$ for the government, a strategy profile $\boldsymbol{\sigma}^{e}$ for the agents, and a belief system $\mathbb{B}$, such that $\boldsymbol{\sigma}^{e}$ and $\Gamma^{e}$ are best responses to each other, given $\mathbb{B}$, and beliefs are derived from Bayesian updating ${ }^{9}$.

\section{Definition 4 (Implementable mechanism)}

$\tau=\left(\tau_{1}, \tau_{2}\right)$ is called an IMPLEMENTABLE MECHANISM if there exists a strategy profile $\boldsymbol{\sigma}$ for the agents and a strategy $\Gamma$ for the government, which constitute an equilibrium and induce an action profile $\gamma=\left(\tilde{\tau}, \tilde{\tau}_{2}^{\prime}\right)$ for the government such that $\tilde{\tau}=\tau$ and $\tilde{\tau}_{2}^{\prime}=\tau_{2}$. Then $\boldsymbol{\sigma}$ and $\Gamma$ are said to support the implementable mechanism $\tau$.

The rest of the paper aims at characterizing the best implementable mechanism, i.e. the tax schedule that maximizes the ex-ante welfare of the continuum of agents.

\section{Truth-telling and partial revelation}

The Revelation Principle is often used to analyze problems of finding and implementing optimal mechanisms in setups with private information (see e.g. Mas-Colell et al. (1995)). However, as is well understood, when the authority exercising the mechanism can revise its design after the revelation of information, non-revealing mechanisms might in fact outperform direct revealing ones. The optimal mechanism might well lead to complete pooling of agents, as for example in Roberts (1984) or Bisin and Rampini (2006).

\footnotetext{
${ }_{9}^{9}$ In the following analysis there will be no need to explicitly derive or condition on these beliefs.
} 
While many advances have in made in classifying models where versions of the Revelation Principle still apply, ${ }^{10}$ the model presented here renders the principle inapplicable. ${ }^{11}$ Nonetheless, some progress can be made to characterize the best implementable mechanism in the game presented above. In this section, I show that while full truthful revelation cannot necessarily be achieved, the best implementable mechanism can always be represented as a truth-telling mechanism. This result allows the problem of finding the optimal mechanism to be presented as one analogous to a standard Mirrlees problem, with the simple addition of choosing an optimal information revelation rule.

Since the government has a utilitarian objective, finding the best implementable mechanism amounts to solving the following problem:

$$
\begin{aligned}
& \max _{\tau} \int_{\Theta} U(\theta \mid \sigma, \tau) d F(\theta) \\
& \text { s.t. } \int_{\Theta} c_{1}(\theta \mid \sigma, \tau)+c_{2}(\theta \mid \sigma, \tau) d F(\theta) \leq \int_{\Theta} y_{1}(\theta)+y_{2}(\theta) d F(\theta) \\
& \quad \boldsymbol{\sigma} \text { is a best response to } \Gamma \\
& \quad \tau_{2} \in \underset{\tau_{2}^{\prime}}{\arg \max _{\Theta} u_{2}\left(\theta \mid \sigma, \tau, \tau_{2}^{\prime}\right) d F(\theta)} \\
& \quad \text { s.t. } \int_{\theta} c_{1}(\theta \mid \sigma, \tau)+c_{2}\left(\theta \mid \sigma, \tau, \tau_{2}^{\prime}\right) d F(\theta) \leq \int_{\Theta} y_{1}(\theta)+y_{2}(\theta) d F(\theta)
\end{aligned}
$$

It maximizes the unweighted sum of agents' utility (3), subject to an aggregate feasibility constraint (4) and a set of incentive compatibility requirements for the agents (5). Moreover, it must satisfy an implementability constraint (6) to ensure that the government does not want to renege on the tax schedule at the beginning of period 2 .

To turn this into a practicable problem, it will be useful to make some progress on the set of incentive compatibility constraints for the agents. To that end, I define a special type of mechanism:

\section{Definition 5 (Direct Mechanism)}

A DIRECT MECHANISM $\tau^{M}$ is a mechanism $\tau=\left(\tau_{1}, \tau_{2}\right)$ where $\tau_{t}: M \times X \mapsto \mathbb{R}$ and $M$ is a partition of the type space $\Theta$.

A direct mechanism is one that is based on a restricted message space $M$. In an equilibrium that induces a direct mechanism, agents report partial information about their type and their tax or transfer payment is based directly on that information. This definition differs from the usual one in that it allows for forms of partial pooling. Note, however, that the definition includes the cases of $M=\Theta$, where agents report

\footnotetext{
${ }^{10}$ See in particular the papers by Bester and Strausz mentioned in the literature review.

${ }^{11}$ This is mainly due to the fact that I analyze the government's commitment problem in a finite horizon game with a continuum of agents.
} 
their true type directly to the government, as well as $M=\{m\}$, a message space with only one element, where agents pool completely and no information is revealed. Denote by $\mathbb{M}$ the set of all possible partitions of $\Theta$.

\section{Theorem 1 (Truth-telling Principle)}

Suppose that $\Gamma$ and $\boldsymbol{\sigma}$ support an implementable mechanism. Then there exists another pair $\Gamma^{*}$ and $\boldsymbol{\sigma}^{*}$ such that $\Gamma^{*}$ induces a direct mechanism and $\boldsymbol{\sigma}^{*}$ induces truth-telling, and $c_{t}(\theta \mid \Gamma, \sigma)=c_{t}\left(\theta \mid \Gamma^{*}, \sigma^{*}\right) \forall \theta, t$.

Proof: See Appendix B.1.

The theorem implies that in the search for the best implementable mechanism one can restrict attention to the set of direct mechanisms and truthful strategies (as opposed to truthfully revealing strategies as in the traditional Revelation Principle). Thus, the problem reduces to:

$$
\begin{aligned}
& \max _{M} \\
& \left\{\max _{\tau^{M}} \int_{\Theta} U\left(\theta \mid \sigma^{*}, \tau(m(\theta))\right) d F(\theta)\right. \\
& \text { s.t. } \int_{\Theta} c_{1}\left(\theta \mid \sigma^{*}, \tau(m(\theta))\right)+c_{2}\left(\theta \mid \sigma^{*}, \tau(m(\theta))\right) d F(\theta) \leq \int_{\Theta} y_{1}(\theta)+y_{2}(\theta) d F(\theta) \\
& m(\theta) \in \arg \max _{\hat{m} \in M} U(\theta, \hat{m} \mid \tau(\hat{m}), \sigma) \quad \forall \theta \in \Theta, m, \hat{m} \in M \\
& \tau_{2} \in \arg \max _{\tau_{2}^{\prime}} \int_{\Theta} u_{2}\left(\theta \mid \sigma, \tau, \tau_{2}^{\prime}\right) d F(\theta) \\
& \text { s.t. } \left.\int_{\theta} c_{1}(\theta \mid \sigma, \tau)+c_{2}\left(\theta \mid \sigma, \tau, \tau_{2}^{\prime}\right) d F(\theta) \leq \int_{\Theta} y_{1}(\theta)+y_{2}(\theta) d F(\theta) \quad\right\}
\end{aligned}
$$

The so restricted problem is easier to solve, and delivers the same equilibrium allocation as the solution to the more general problem would. Notice that by collecting only limited information the government automatically commits itself to not using any further information not included in the messages $m$. The optimal choice of information revelation is based on exactly that consideration: to credibly limit the ex-post temptation of reneging on the promised tax schedule. Thus, one can think of the problem as first choosing the optimal amount and form of information to be collected (the outer problem) and then choosing a tax and transfer schedule based on that limited information (the inner maximization).

Beside the technical equivalence, it is useful to think about the economic interpretation of direct mechanisms in this context: In reality, when taxes and transfers are conditioned on private information, the government must decide how people report this information. For example, the first step to implementing an income tax is to design a tax return form that people use to report their income. The government 
can choose an institutional design that asks agents only for coarse information. The tax return form could, for example, ask for an agent's approximate income, or an income bracket.

The problem can be further simplified by employing a more general mechanism design approach (as e.g. in Bester and Strausz (2001) and Skreta (2007, 2010)), where a fictitious mechanism designer is in charge of choosing strategy sets for the agents and for the government (taking into account the government's commitment problem). Accordingly, let $\boldsymbol{M}=(\boldsymbol{\sigma}, \Gamma) \in \boldsymbol{\Sigma} \times G$ denote a fictitious mechanism, i.e. the fictitious designer's choice of strategies for the agents and the government.

The great advantage of this approach is that the traditional Revelation Principle allows attention to be restricted to direct fully revealing fictitious mechanisms. This allows me to write the problem of the fictitious planner as maximizing the same objective as the government, (7), subject to aggregate feasibility (8), and the implementability constraint (10), but replacing the set of incentive compatibility constraints (9) by

$$
\begin{aligned}
& \theta \in \arg \max _{\hat{\theta}} U(\theta, \hat{\theta} \mid \tau(m(\hat{\theta})), \sigma) \quad \forall \theta, \hat{\theta} \in \Theta \\
& m: \Theta \mapsto M \in \mathbb{M}
\end{aligned}
$$

These two constraints ensure that agents find it optimal to directly reveal their type truthfully to the fictituous planner, while the government can base its actions (and in particular its choice of the tax schedule) only on parts of this information. The two problems are equivalent, since the fictitious designer is able to guarantee that the reported information is encoded by the information revelation rule $m$ before being transmitted to the government.

Reformulating the general problem (3) through (6) into a problem of maximizing (7), subject to (8), (10), (12), and (13) allows me to explicitly study situations where the government has limited commitment in the sense that it can commit not to exploit a limited amount of information. The fictitious planner's choice of the information revelation rule makes this explicit: The function $m$ could be such that no information is revealed (i.e. $m$ is constant), full information is revealed (i.e. $m$ is the identity function), but could also allow for any form of partial information revelation (i.e. $m$ is constant over some subset of $\Theta$ so that some agents are pooled together).

It is without loss of generality to restrict the search for $m$ to functions that are weakly increasing in $\theta .{ }^{12}$ Moreover, I normalize $m$ such that

$$
m(\hat{\theta})=\hat{\theta} \quad \text { for } \hat{\theta}=\min \{\theta: m(\theta)=m\}^{13}
$$

\footnotetext{
${ }^{12}$ This only excludes the possibility that non-adjacent types are pooled together, which could never be optimal due to the monotonicity inherent in the setup.

${ }^{13}$ This just means that when some types are pooled together, the message sent to the government is normalized to be equal to the lowest type in that group.
} 
The results of this section allow me to transform the game between the government and the agents into a relatively simple mechanism design problem. They are applicable beyond the model of this paper, in models that satisfy the assumptions on preferences and the type distribution made in Section 2. The remainder of the paper focuses on analyzing characteristics of the information revelation rule $m$ as a proxy for the commitment power of the government, and on how they depend on the severity of imperfection in the financial market agents trade in.

\section{Benchmarks}

In this section, I provide two benchmarks: The optimal allocation for a government with an exogenous commitment device, and the optimal allocation for a government without commitment when there are no financial markets for agents to trade in. For the government in the model economy, the only difference from the planned economy arises from the private information constraints. The resulting difficulties then are exacerbated by the government's lack of commitment with respect to using acquired information. The benchmarks serve to illustrate the severance of the commitment problem and the potential of the imperfect financial market to alleviate it.

\subsection{Government with exogenous commitment}

When the government is assumed to be able to commit to a tax schedule over time through some exogenous commitment device, the traditional Revelation Principle can directly be applied, i.e. we can focus on direct mechanisms that induce full truthful revelation.

\section{Lemma 1 (Information Revelation with Commitment)}

If the government can fully commit, the optimal information revelation rule is such that complete information about types is revealed: $m(\theta)=\theta$ for all $\theta \in \Theta$.

Proof: Follows directly from the Revelation Principle. ${ }^{14}$

The government's problem then simplifies to

$$
\begin{aligned}
& \max _{\tau} \int_{\Theta} \sum_{t=1}^{2} u\left(t \theta+\tau_{t}(\theta)\right) d F(\theta) \\
& \text { s.t. } \int_{\Theta}\left[\tau_{1}(\theta)+\tau_{2}(\theta)\right] d F(\theta) \leq 0 \\
& \quad \theta \in \arg \max _{\hat{\theta}} \sum_{t=1}^{2} u\left(t \theta+\tau_{t}(\hat{\theta})\right) \quad \forall \theta, \hat{\theta} \in \Theta .
\end{aligned}
$$

For future reference, I denote the solution to this problem with superscript EC (for exogenous commitment).

\footnotetext{
${ }^{14}$ See for example Myerson (1979) and Harris and Townsend (1981).
} 


\section{Lemma 2 (Optimal Allocation with Exogenous Commitment)}

At the optimal allocation with exogenous commitment:

(i) There is partial social redistribution - total consumption is increasing in type, but less steeply than under autarky:

$$
0<\frac{\partial\left(c_{1}^{E C}(\theta)+c_{2}^{E C}(\theta)\right)}{\partial \theta}<3
$$

(ii) The degree of smoothness of consumption increases with type; only the highest type smooths consumption perfectly:

$$
\begin{aligned}
& c_{1}^{E C}(\bar{\theta})=c_{2}^{E C}(\bar{\theta}) \\
& c_{1}^{E C}(\theta)<c_{2}^{E C}(\theta) \quad \& \quad \frac{\frac{\partial c_{1}^{E C}(\theta)}{c_{2}^{E C}(\theta)}}{\partial \theta}>0 \quad \forall \theta<\bar{\theta}
\end{aligned}
$$

Proof: See Appendix A.1.

When the government is able to commit to not changing the announced transfer schedule after information is revealed, it is optimal to implement a fully separating allocation. The setup resembles the traditional static Mirrlees (1971) model, where the desire to smooth consumption efficiently over time corresponds to the optimal labor/leisure choice in Mirrlees' setup. The optimal allocation depicts the classic trade-off between allocative efficiency and informational rent extraction under adverse selection. Even though both forms of redistribution (across the population as well as across time) are in the government's interest, the private information constraints introduce a trade-off between the two. Since the elasticity of intertemporal substitution is constant, all types are willing to give up the same fraction of their total income for smoothing consumption over time. In absolute terms, agents with higher income types would pay more for consumption smoothing than lower income types. The government uses the degree of smoothness as an incentive for higher types to reveal themselves and agree to higher contributions to social redistribution - the ability to do so crucially depends on the government being able to commit to the allocation ex-ante. Perfect consumption smoothing for the highest type is analogous to Mirrlees' (1971) "efficiency at the top" result; non-perfect smoothing for all other types refers to the distortion of efficiency for all types other than the highest.

Notice that here it does not matter whether there are markets for agents to trade in. Since contracts in the market are fully observable to the government, it could simply condition the tax schedule on the contracts agents write. Thus, the exogenous commitment power enables the government to prevent agents from using the market to allocate their resources in any way that does not comply with the government's chosen optimal allocation.

\subsection{Government without commitment}

If policy is chosen sequentially and the government cannot commit to a schedule ex-ante, the equilibrium tax system must satisfy the implementation constraint (6). 
Without the presence of financial markets for agents to trade in, this leads to the following information revelation at the optimal allocation:

\section{Lemma 3 (Information Revelation without Commitment)}

If the government cannot commit, the optimal information revelation rule is such that no information about types is revealed: $m(\theta)=\underline{\theta}$ for all $\theta$.

Proof: See Appendix A.2.

When the government cannot commit not to exploit information about types in period 2, it does not find it optimal to implement any separation at all. The argument of the proof is as follows: Because of the commitment constraint (6), the government loses the ability to offer any separation in period 2 consumption; since the necessity to provide incentives for agents to reveal their type truthfully vanishes after the first period, the government would always change the announced allocation when provided with the opportunity to do so. Such deviation from the ex-ante optimal contract, though, is not beneficial for all agents. A government offering above mean type agents a worse allocation after learning their true income is known as the ratchet effect. ${ }^{15}$ Agents anticipate this, so incentives for truthful revelation need to be provided through transfers in period 1. However, to achieve any separation in types, the incentive payments would have to be so high that redistribution would go from the bottom to the top of the income distribution - inequality would rise compared to autarky. Thus, complete pooling is the optimal choice of information revelation. ${ }^{16}$ Consequently, no redistribution across agents (i.e. social insurance) and almost no redistribution across time (i.e. consumption smoothing) will be implemented. I denote this allocation with superscript NC (for no commitment).

\section{Lemma 4 (Optimal Allocation without Commitment)}

At the optimal allocation without commitment:

(i) There is no social redistribution - agents consume their total endowment; total consumption increases in type as under autarky:

$$
c_{1}^{N C}(\theta)+c_{2}^{N C}(\theta)=3 \theta \quad \forall \theta
$$

(ii) Only one type $\theta^{*}$ receives perfectly smooth consumption:

$$
\begin{aligned}
& c_{1}^{N C}\left(\theta^{*}\right)=c_{2}^{N C}\left(\theta^{*}\right)=\frac{3}{2} \theta^{*} \\
& c_{1}^{N C}(\theta)=\theta+\frac{1}{2} \theta^{*} \neq c_{2}^{N C}(\theta)=2 \theta-\frac{1}{2} \theta^{*} \quad \forall \theta \neq \theta^{*} .
\end{aligned}
$$

\footnotetext{
${ }^{15}$ The insight that the only incentive-compatible sequence of spot contracts is one without dynamic insurance is due to Townsend (1982).

${ }^{16}$ Brett and Weymark (2011) show that in an economy where agents have an additional choice of labor supply, and with a discrete number of types, (partial) separation might sometimes be optimal. Moreover, different functional forms of preferences and the income process might lead to some separation through first period transfers being optimal. Even in such economies, though, the government's lack of commitment worsens welfare compared to the constrained efficient allocation with commitment.
} 
Proof: When no information about types is revealed, the only instrument for increasing welfare is handing out non-differential transfers. The government will choose these optimally to smooth consumption for one particular type $\theta^{*}$. All other agents smooth only the part of their income equal to that of type $\theta^{*}$ and consume their remaining income on the spot.

In this economy, the government's lack of commitment has dramatic implications. Not only is the government unable to implement any social redistribution, the resulting allocation is also very inefficient: Even though transferring resources across time is costless, this technology remains almost unused, because it would require the revelation of private information. Roberts' (1984) insight applies in this economy.

\section{Limited commitment due to market imperfec- tion}

In this section, I derive some key characteristics of the best implementable tax schedule when the government has no commtiment and agents can access imperfect fiancial markets. The aim is to show that if agents are able to trade, the government might effectively gain commitment, the degree of which depends on the severity of the market imperfection measured by $D$.

When agents trade in financial markets, the benevolent government takes their contractual positions into account. Thus, the planning problem of the fictitious designer to find the best implementable mechanism is to maximize

$$
\max _{\tau} \int_{\Theta} \sum_{t=1}^{2} u_{t}\left(y_{t}(\theta)+\tau_{t}(m(\theta))+h_{1}(m(\theta))-b_{1}(m(\theta))\right) d F(\theta)
$$

subject to aggregate feasibility (restated in terms of the government's budget)

$$
\int_{\Theta} \tau_{1}(m(\theta))+\tau_{2}(m(\theta)) d F(\theta) \leq 0
$$

and incentive compatibility

$$
\theta \in \arg \max _{\hat{\theta} \in \Theta} U(\theta, \hat{\theta} \mid \tau(m(\hat{\theta})), \sigma) \quad \forall \theta, \hat{\theta} \in \Theta
$$

where a particular information revelation rule $m: \Theta \mapsto M \in \mathbb{M}$ is promised. Lastly, the mechanism $\tau$ must satisfy the implementability requirement (10) to ensure that the government does not choose to deviate from the promised mechanism at the beginning of the second period. Thus, the constraint needs to explicitly take into account what happens if the announced tax schedule is changed. Generally, choosing to renege on its promise after it learns new information about the agents is of no inherent consequence. It is only due to the agents' involvement in the imperfect financial market that the government might suffer a loss from changing the tax schedule. In particular, if an agent cannot afford the payment $b_{2}$ he agreed to provide to the lender in period 2 , he is forced to resell his claim $h_{2}$ - and incur a loss of $D$. 
It is without loss of generality to assume that an agent's modified contract specifies $h_{2}^{\prime}=0$. Yet, because of individual enforceability, the lender remains in power to collect any outstanding balance $d_{1} \equiv h_{1}-b_{1}$ from period 1 as well as administer the access (or renegotiation) cost D. It cannot, however, enforce a bailout, so that

$$
b_{2}^{\prime}=\min \left\{d_{1}+D, y_{2}+\tau_{2}^{\prime}\right\}
$$

Further, because of the renegotiation cost, an agent would obviously never choose to renegotiate a contract unless he is forced to by a new tax schedule that leaves him without the means to fulfill his commitments. Notice that assumption (A3) rules out the possibility that agents scheme against the bank and plan a default. While this is certainly an unrealistic assumption, it simplifies matters greatly. A model with the more realistic assumption of lenders not being able to observe types is discussed in section 8 , the results presented here remain true. ${ }^{17}$

With these features of financial contracts, the implementability constraint (10) becomes

$$
\begin{gathered}
\tau_{2} \in \arg \max _{\tau_{2}^{\prime}} \int_{\Theta} \\
u\left(y_{2}(\theta)+\tau_{2}^{\prime}(m(\theta))+h_{2}(m(\theta))-b_{2}(m(\theta))\right) \\
u\left(y_{2}(\theta)+\tau_{2}^{\prime}(m(\theta))-\left(d_{1}(m(\theta))+D\right)\right) \\
\text { s.t. } \left.\int_{\Theta} \tau_{1}(m(\theta))+y_{2}^{\prime}(\theta)+\tau_{2}^{\prime}(m(\theta)) \geq b_{2}(\theta)\right\}
\end{gathered}
$$

Examining the problem leads to the main result of the paper:

\section{Proposition 1 (Effective Commitment)}

Suppose that $D>0$. Then there exists an equilibrium in which all agents sign gross contracts with $b_{2}(\theta)=y_{2}(\theta)+\tau_{2}(\theta)$ and that supports a fully revealing implementable mechanism that sustains separation in the second period such that:

$$
u^{\prime}\left(c_{2}(\underline{\theta})\right)\left(c_{2}(\bar{\theta})-c_{2}(\underline{\theta})-D\right) \leq u\left(c_{2}(\bar{\theta})\right)-u\left(c_{2}(\underline{\theta})\right)
$$

Proof: See Appendix B.2.

The proposition states that as long as markets are slightly imperfect, there exists a mechanism in which the government is able to abstain from using the information it acquired about agents and reneging on the promised tax schedule. Agents pledging their entire net income in private contracts that cannot costlessly be changed effectively provides the government with a commitment device.

Condition (21) states how much incentive provision is possible in this fully separating equilibrium. The intuition is simple: It equates the marginal benefit from

\footnotetext{
${ }^{17}$ In fact, lenders only care about agents not lying "upward". In the extension, I show that a lender can solve his information constraint by instituting a down payment to verify that an agent is at least of the type he claims to be.
} 
deviating from the promised allocation (as measured by the marginal utility of the lowest type who would be distributed toward times the amount of resources available for redistribution) with the marginal cost of such a deviation (the utility loss of the highest type who would have to default). For a given functional form of preferences, the higher the default costs, the larger the tolerable difference in consumption levels. Conversely, for given costs $D$, the more concave the utility function is, the higher would be the ex-post welfare gain from redistribution and so the less effective commitment is provided by the market imperfection. Note that when $D=0$, the case of no commitment is recovered: As long as the utility function is strictly concave, condition (21) is then only satisfied if $c_{2}(\underline{\theta})=c_{2}(\bar{\theta})$. Thus, when markets are perfect in the sense that agents can simply resell their contracts without a loss, then no fully revealing mechanism with separation in the second period is implementable.

\section{Corollary 1}

Aggregate welfare achieved under the best implementable mechanism is always weakly increasing in $D$.

Proof: With being able to effectively commit to a fully separating allocation in period 2, the government gains an additional policy instrument: It is able to provide incentives for information revelation by promising a differential consumption allocation in period 2. As is straight forward to see from condition (21), the degree of separation the government can sustain is weakly increasing in $D$. On the other hand, this policy instrument doesn't have to be used, so that the government cannot do worse in implementing a tax schedule that maximizes welfare than if $D=0$.

Agents' involvement in imperfect markets can improve the government's ability to implement social redistribution. This is the core result of the paper. As is stated in Proposition 1, for this channel to work, agents have to pledge all their income in period 2 in a financial contract. Since the effective commitment for the government stems from the threat of default losses should it renege on the promised tax schedule, it is quite obvious that when agents don't sign such contracts, the mechanism won't work. However, since all financial contracts are observable to the government, agents find it optimal to pledge their income to the bank to protect it from being taken away by the government. One might argue that in reality agents cannot easily asses the government's commitment power, and so won't sign contracts simply to induce commitment for the government. Note, however, that it would be easy for the government to induce agents to sign contracts, by offering very non-smooth allocations. Moreover, in reality, a large fraction of household income is indeed pledged in contracts that cannot costlessly be changed (see Chetty and Szeidl (2007) for an extensive study).

\section{Limited use of information}

Corollary 1 only shows a weak welfare improvement. In fact, a small degree of imperfection (i.e. a small $D$ ) only allows for a small degree of separation in the second period, which might not be enough to provide incentives for high types to reveal 
themselves truthfully ex-ante: While Proposition 1 shows that with a positive cost $D$ the government is always able to sustain full separation in the second period, it adds the qualification that the spread between the lowest and highest type's consumption cannot be too high, depending on the renegotiation costs $D$. However, promising a small advantage for high types might not be enough to satisfy their incentive constraints against pretending to be a lower type. Thus, even when all conditions of Proposition 1 are met, the government might not choose to offer a mechanism that fully separates agents in the second period, even though it could.

In this section, I show that instead of effectively committing to a fully separating allocation with a small spread in consumption levels, the government might choose to implement an only partially revealing mechanism. In that sense, the effective limited commitment translates into a limited information intake, with its form chosen such that the government's temptation to misuse information ex-post is exactly offset by the potential default loss.

\section{Corollary 2 (Limited Information Revelation)}

Suppose that $D>0$. Then there exists an equilibrium in which all agents sign gross contracts with $b_{2}(m(\theta))=y_{2}(m(\theta))+\tau_{2}(m(\theta))$ and that supports a partially revealing implementable mechanism with an information revelation rule such that agents are pooled above but separated below a cutoff type $\tilde{\theta}$ :

$$
\begin{array}{ll}
m(\theta)=\theta & \forall \theta \leq \tilde{\theta} \\
m(\theta)=\tilde{\theta} & \forall \theta>\tilde{\theta}
\end{array}
$$

The cutoff $\tilde{\theta}$ and transfers $\tau$ must be such that

$$
u^{\prime}\left(c_{2}(\underline{\theta})\right)\left(c_{2}(\tilde{\theta})-c_{2}(\underline{\theta})-D\right) \leq u\left(c_{2}(\tilde{\theta})\right)-u\left(c_{2}(\underline{\theta})\right)
$$

Proof: See appendix B.3.

Corollary 2 is not about the optimality of a specific implementable mechanism. Rather, it highlights that a commitment device with only limited effectiveness (like a small market imperfection) might still be of use. If the difference in consumption levels that the government can effectively commit to sustain is not enough to persuade the highest type of truthful revelation, it might still be enough to at least elicit a limited amount of information. High type agents, instead of having to report their exact income in exchange for little incentive payments, could be asked to only report that their income exceeds a certain threshold. That way, the government gains the ability to at least draw on some of their income for redistribution.

Patterns of partial information revelation are implemented in many real world tax codes. In the US, for example, social security relevant wages are capped, income in excess of the cap is not being considered for the direct federal redistribution scheme. One can also imagine other forms of partial pooling to be optimal, e.g. stepwise pooling into income brackets. 
The optimal form of the information revelation rule in the best implementable mechanism of course depends on the exact form of the utility function, on the distribution of types, but also on specifics of the income process. The assumptions made for this stylized model essentially restrict attention to the more interesting cases when the lack of commitment indeed has severe consequences: As shown in section 5, the government's lack of commitment here leads to the inefficient outcome of no social redistribution at all.

\section{Corollary 3}

Aggregate welfare achieved under the best implementable mechanism is strictly higher when $D>0$ compared to $D=0$. Moreover, there exists a lower bound on the spread of the type distribution $(\bar{\theta}-\underline{\theta})$ such that the best implementable mechanism implements some form of partial pooling whenever inequality exceeds that bound.

Proof: See Appendix B.4.

The results in this section demonstrate that structural characteristics of the economic environment a government operates in, like the presence of financial markets and the degree of their imperfection, matter for its ability to commit to tax policy over time.

With some market imperfection, limited commitment can always be achieved. Corollary 3 shows that if inequality is sufficiently large, this effective limited commitment will manifest itself in a limited information intake. Using this limited amount of information, the government can at least achieve some redistribution and so welfare is strictly improved.

Comparing the achievable allocation to the benchmarks derived in section 5 , it is worth noting that the government cannot achieve the same allocation as with an exogenous commitment device (benchmark EC). As derived in section 5.1, the government with an exogenous commitment device would use the degree of consumption smoothness as an incentive for higher types to reveal themselves. With giving agents access to financial markets, the government loses this policy instrument; agents can use the market to allocate their resources over time as they see fit. However, it gains the ability to (partially) commit and improve over the no commitment benchmark (NC) derived in section 5.2. Compared to this allocation, both social redistribution and efficiency (i.e. the transferring of resources over time) are improved.

\section{Robustness discussion}

The main result of the paper is of qualitative nature and shows how the economic environment a government operates in can help explain its ability to commit to tax policy over time. The model I presented to derive this result is very stylized. While the exact allocation implemented by the best mechanism depends on the specific assumptions made about the model economy, the result that commitment can be gained through agents' using an imperfect financial market is robust to relaxing 
them. In this section, I discuss a few possible extensions.

\subsection{Preferences, income process and default costs}

In the model setup, I assumed that agents are not discounting the future, and the government is maximizing an objective with equal Pareto weights on all agents. These two assumptions are for notational convenience only. As long as agents value the future at least a little bit (i.e. $\beta>0$ ) and as long as all agents have a positive weight in the government's objective, adding discounting and a non-uniform distribution of Pareto weights will not change the results qualitatively. Of course, the exact amount and form of limited information optimally collected by the government would change.

The functional form of preferences has been chosen to ease the comparison with the no commitment benchmark. With constant intertemporal elasticity of substitution, the government without commitment always optimally pools all agents and consequently provides no social redistribution. The government could of course ask for information and try to implement a a type-differential tax schedule. All incentives for agents to reveal information would have to be provided in the first period, since without commitment the government will equalize everyone in $t=2$. One can think of preference functions where the optimal allocation would take this form (in particular when higher type agents do not value smooth consumption). Even then, however, the introduction of an imperfect financial market would still work as a commitment device and enable the government to commit to incentive payments (in the form of a differentiated tax schedule) also in the second period. Of course, it is even possible that agents have preferences that perfectly coincide with the government's objective in both periods, in which case the commitment problem would not actually be a problem. Obviously, if that was the case, the mechanism discussed here would be of no use for the government and not change the implemented policy.

Another restrictive assumption is the specification of the income process. In the model economy, every agent would like to borrow in period 1 to smooth consumption. Other forms of income processes will yield the same result, as long as there is some reason for agents to actually use the financial market. The commitment power of the government was endogenously gained through the fact that agents held contracts that cannot costlessly be changed. It is even conceivable then that this mechanism operates in a closed economy, where some agents receive a higher income in the first and some in the second period and they are lending to each other. A technical difficulty would only arise if another dimension of type-differentiation was introduced (and we would have to keep track of multi-dimensional types).

Moreover, the central characteristic of markets on which the whole commitment mechanism hinges is modeled as an exogenous default cost that is fixed per head. In fact, the results remain unchanged as long as the costs are weakly increasing in the amount of default - an assumption that is more realistic. It would be interesting to investigate models in which the default costs are endogenous. The only restriction to them serving as a commitment device for the government is that they cannot be 
at the discretion of the government. If the taxing authority would be able to simply announce default costs and otherwise had no commitment, it would obviously choose to announce very high costs in period 1 only to set them to zero in period 2 .

\subsection{Alternative Model: Lenders with information constraints}

With assumption (A3), the model abstracts from any additional adverse selection problem lenders in the financial market might face. Here I discuss an alternative setup that is more realistic, yet leaves the results derived in the paper unchanged. The complete analysis is done in Simon (2012).

Suppose that the financial market is competitive, but lenders cannot observe agents' types either, so that type-specific borrowing constraints are not exogenously possible. An agent might then misrepresent his type to the bank as well as to the government. Lenders would then offer contracts that condition on the agent's type report $m$, rather than his true type.

This opens up the possibility that an agent reports a much higher type to take advantage of a high borrowing limit and plans a sure default. To avoid such adverse selection, lenders would like to verify that agents are at least of the type they claimed. This is easily achievable with a down payment: Lenders in this environment will offer contracts that require a payment

$$
b_{1}(m)=y_{1}(m)+\tau_{1}(m)
$$

by the agent that has sent report $m$ about his type. This proof of solvency acts as a screening device, i.e. it signals to the bank that the agent is at least of the type he claimed he was. Competition then ensures that the agent can find a bank offering a contract with a borrowing limit that reflects the exact net income of the type he announced. Banks cannot gain anything by offering contracts that do not require a down payment, since only agents who have misreported their type would sort into those.

Notice that a contract with a down payment in period 1 is a form of gross contract that is within the set of contracts analyzed in the main text. Therefore, the results derived remain unchanged.

While generally signaling problems with two principals are difficult, the specific circumstances here make it easy to solve: The agent's objectives to lie to the government and the lender respectively are exactly opposite. Or in other words, lenders care about the upward incentive constraints, while the government care about the downward incentive constraints. Solving one of these problems therefore doesn't interfere with the agents' incentives to lie along the other dimension.

\subsection{Conclusion}

In the presence of private information, the ability of a government to implement social redistribution crucially depends on its power to commit to future policy. In 
reality, however, there is little reason to believe that governments possess some exogenous commitment device. Instead, commitment must stem from the environment the government operates in. The literature has focused on political economy constraints as mechanisms for commitment. In contrast to that, this paper highlights the fact that also the economic environment might enhance the commitment power of the government.

In developed market economies, individuals use financial markets to allocate their resources over time. In economic theory, the presence of such markets has been shown to decrease the set of policy instruments available to the government. Moreover, no matter how developed, markets in reality are incomplete, a flaw that is commonly expected to yield suboptimal outcomes. This paper argues to the contrary that the frictions resulting from market incompleteness may in fact be very beneficial for redistributive policy. When the government has no commitment power, agents trading in imperfect financial markets enhances the set of allocations the government can achieve. It is precisely the market's incompleteness that leads to agents entering small individual commitments, which then add up to an effective commitment device for the government, thereby enabling more social redistribution.

For the described mechanism to work, the market agents trade in must be imperfect, in the sense that costs result from renegotiating contracts. In other words, by using financial markets to allocate their resources over time, agents must enter individual consumption commitments. Empirical research by Chetty and Szeidl (2007) shows that this is indeed the case: As much as $65 \%$ of the average US household income are devoted to consumption commitments that cannot costlessly be changed. Those include not only mortgage or other loan payments. Also the consumption of durables, insurances or energy contracts can typically not be adjusted instantly or without cost. In that sense, the interpretation of market imperfection goes beyond direct default costs. Rather, it is a measure of incompleteness that can be interpreted much more broadly. Any time that agents make decisions (labor supply decisions, investment in human capital etc.) that set them on a specific income and consumption path which does not cover all contingencies, adjustments to policy changes are costly and could therefore yield some form of commitment for the government. 


\section{References}

Acemoglu, D., Golosov, M. and Tsyvinski, A.: 2006, Markets versus governments: Political economy of mechanisms, NBER Working Paper WP 12224.

Acemoglu, D., Golosov, M. and Tsyvinski, A.: 2008, Political economy of mechanisms, Econometrica 76, 619-641.

Acemoglu, D., Golosov, M. and Tsyvinski, A.: 2010, Dynamic mirrlees taxation under political economy constraints, Review of Economic Studies 77(3), 841-881.

Berliant, M. and Ledyard, J. O.: 2005, Optimal dynamic nonlinear income taxes with no commitment, Working Paper.

Bester, H. and Strausz, R.: 2000, Imperfect commitment and the revelation principle: The multi-agent case, Economics Letters 69(2), 165-171.

Bester, H. and Strausz, R.: 2001, Contracting with imperfect commitment and the revelation principle: The single agent case, Econometrica 69(4), 1077-1098.

Bester, H. and Strausz, R.: 2007, Contracting with imperfect commitment and noisy communication, Journal of Economic Theory 136(1), 236-259.

Bisin, A. and Rampini, A.: 2006, Markets as beneficial constraints on the government, Journal of Public Economics 90, 601-629.

Brett, C. and Weymark, J. A.: 2011, Optimal nonlinear taxation of income and savings without commitment, Working Paper .

Chetty, R. and Szeidl, A.: 2007, Consumption commitments and risk preferences, Quarterly Journal of Economics 122(2), 831-877.

Dasgupta, P., Hammond, P. and Maskin, E.: 1979, The implementation of social choice rules: Some general results on incentive compatibility, Review of Economic Studies 46(2), 185-216.

Fudenberg, D. and Tirole, J.: 1991, Game Theory, MIT Press, Cambridge.

Golosov, M., Tsyvinski, A. and Werning, I.: 2006, New dynamic public finance: A user's guide, NBER Macroeconomic Annual .

Golosov, M. and Tsyvinsky, A.: 2007, Optimal taxation with endogenous insurance markets, Quarterly Journal of Economics 122(2), 487-534.

Hammond, P.: 1987, Markets as constraints: multilateral incentive compatibility in continuum economies, Review of Economic Studies 54, 399-412.

Harris, M. and Townsend, R. M.: 1981, Resource allocation under asymmetric information, Econometrica 49, 33-69.

Holmström, B. and Myerson, R. B.: 1983, Efficient and durable decision rules with incomplete information, Econometrica 51(6), 1799-1819. 
Mas-Colell, A., Whinston, M. and Green, J.: 1995, Microeconomic Theory, Oxford University Press.

Mirrlees, J. A.: 1971, An exploration in the theory of optimum income taxation, review of Economic Studies 38, 175-208.

Myerson, R.: 1979, Incentive compatibility and the bargaining problem, Econometrica $47,61-73$.

Roberts, K.: 1984, The theoretical limits to redistribution, Review of Economic Studies 51, 177-195.

Simon, J.: 2012, Financial markets as a commitment device for the government, EUI Working Paper (2012/12).

Skreta, V.: 2007, Sequential optimal mechanisms, Review of Economic Studies 73, 1085-1111.

Skreta, V.: 2010, Optimal auction design under non-commitment, Working Paper.

Townsend, R. M.: 1982, Optimal multiperiod contracts and the gain from enduring relationships under private information, Journal of Political Economy 90(6), 1166-86.

\section{A Appendix: Benchmark proofs}

\section{A.1 Proof of Lemma 2 - government with commitment}

First, notice that the first-best allocation is not incentive compatible: From an agent's point of view, his consumption allocation $x_{1}=x_{2}=x$ would be fixed, no matter what type he reports. He then chooses to report type $\hat{\theta}$ to solve

$$
\max _{\hat{\theta}} u(x+(\theta-\hat{\theta}))+u(x+2(\theta-\hat{\theta})) .
$$

Since utility is time-separable and per-period utility is strictly increasing, first and second period consumption are not perfect complements. Thus, every type has an incentive to hide income from the government, thereby receiving the same allocation of consumption as under truth-telling $x$ plus the extra hidden income $t(\theta-\hat{\theta})$. Each agent then optimally chooses tho report the lowest possible type $\underline{\theta}$. Full social insurance and perfect smoothing cannot be implemented.

Consider next the allocation with perfect smoothing over time for all types and no redistribution across agents, i.e. $x_{1}(\theta)=x_{2}(\theta)=\frac{3}{2} \theta$. This allocation is incentive compatible. The agent solves

$$
\max _{\hat{\theta}} u\left(\theta+\frac{1}{2} \hat{\theta}\right)+u\left(2 \theta-\frac{1}{2} \hat{\theta}\right)
$$


Optimality requires

$$
\begin{array}{r}
\frac{\partial}{\partial \hat{\theta}}=\frac{1}{2}\left(u^{\prime}\left(\theta+\frac{1}{2} \hat{\theta}\right)-u^{\prime}\left(2 \theta-\frac{1}{2} \hat{\theta}\right)\right)=0 \\
u^{\prime}\left(\theta+\frac{1}{2} \hat{\theta}\right)=u^{\prime}\left(2 \theta-\frac{1}{2} \hat{\theta}\right) \\
\rightarrow \hat{\theta}=\theta .
\end{array}
$$

The last step follows because $u(\cdot)$ is strictly concave. At this allocation, per-period consumption $x_{t}(\theta)=t \theta+\tau_{t}(\theta)$ increases with slope $\frac{3}{2}$. The concavity of the utility function implies that it is strictly optimal for all agents to report the true type. This means that the incentive constraints are not binding for any type. Thus, there is room for welfare increasing redistribution across agents. It follows directly that total consumption will be increasing less than under autarky, i.e.

$$
\frac{\partial\left(x_{1}(\theta)+x_{2}(\theta)\right)}{\partial \theta}<3
$$

Next, I will derive the properties of the optimal allocation that result from such redistribution. Redistributing across agents from top to bottom requires that the sum of transfers $\tau_{1}(\theta)+\tau_{2}(\theta)$ should be decreasing in type, i.e.

$$
\frac{\partial\left(\tau_{1}(\theta)+\tau_{2}(\theta)\right)}{\partial \theta}=\tau_{1}^{\prime}(\theta)+\tau_{2}^{\prime}(\theta)<0 \leftrightarrow-\frac{\tau_{2}^{\prime}(\theta)}{\tau_{1}^{\prime}(\theta)}>1
$$

for all types $\theta<\bar{\theta}$. Just at the highest type, the contribution to the social redistribution system need not be increasing, i.e. $\tau_{1}(\bar{\theta})=-\tau_{2}(\bar{\theta})$.

When agents choose which type to report, they solve

$$
\max _{\hat{\theta}} u\left(\theta+\tau_{1}(\hat{\theta})\right)+u\left(2 \theta+\tau_{2}(\hat{\theta})\right) .
$$

A necessary condition for incentive compatibility thus is that the first order condition of this problem be zero at $\hat{\theta}=\theta$ :

$$
\frac{u^{\prime}\left(\theta+\tau_{1}(\theta)\right)}{u^{\prime}\left(2 \theta+\tau_{2}(\theta)\right)}=\frac{-\tau_{2}^{\prime}(\theta)}{\tau_{1}^{\prime}(\theta)} .
$$

First, notice that (27) together with (28) and the concavity of $u(\cdot)$ imply that $x_{1}(\theta)<x_{2}(\theta)$ for all types $\theta<\bar{\theta}$, but $x_{1}(\bar{\theta})=x_{2}(\bar{\theta})$. That is, perfect smoothing for the highest type is optimal and smoothing is distorted for all other types.

For (28) to also be sufficient for incentive compatibility, it must be the case that the second order condition for optimality is also satisfied at $\hat{\theta}=\theta$.

$$
u^{\prime \prime}\left(\theta+\tau_{1}(\theta)\right)\left(\tau_{1}^{\prime}\right)^{2}+u^{\prime}\left(\theta+\tau_{1}(\theta)\right) \tau_{1}^{\prime \prime}+u^{\prime \prime}\left(2 \theta+\tau_{2}(\theta)\right)\left(\tau_{2}^{\prime}\right)^{2}+u^{\prime}\left(2 \theta+\tau_{2}(\hat{\theta})\right) \tau_{2}^{\prime \prime}<0
$$

Further differentiating (28) yields

$$
u^{\prime \prime}\left(\theta+\tau_{1}(\theta)\right) \tau_{1}^{\prime} x_{1}^{\prime}+u^{\prime}\left(\theta+\tau_{1}(\theta)\right) \tau_{1}^{\prime \prime}+u^{\prime \prime}\left(2 \theta+\tau_{2}(\theta)\right) \tau_{2}^{\prime} x_{2}^{\prime}+u^{\prime}\left(2 \theta+\tau_{2}(\hat{\theta})\right) \tau_{2}^{\prime \prime}=0
$$


where $x_{t}(\theta)=t \theta+\tau_{t}(\theta)$ and so $x_{t}^{\prime}(\theta)=t+\tau_{t}^{\prime}(\theta)$.

Combining (29) and (30) gives the following monotonicity requirement

$$
u^{\prime \prime}\left(\theta+\tau_{1}(\theta)\right) \tau_{1}^{\prime} x_{1}^{\prime}+u^{\prime \prime}\left(2 \theta+\tau_{2}(\theta)\right) \tau_{2}^{\prime} x_{2}^{\prime}>u^{\prime \prime}\left(\theta+\tau_{1}(\theta)\right)\left(\tau_{1}^{\prime}\right)^{2}+u^{\prime \prime}\left(2 \theta+\tau_{2}(\theta)\right)\left(\tau_{2}^{\prime}\right)^{2}
$$

which simplifies to

$$
u^{\prime \prime}\left(\theta+\tau_{1}(\theta)\right) \tau_{1}^{\prime}+2 u^{\prime \prime}\left(2 \theta+\tau_{2}(\theta)\right) \tau_{2}^{\prime}>0 .
$$

A sufficient condition for this to hold is that

$$
2>\frac{u^{\prime \prime}\left(x_{1}\right)}{u^{\prime \prime}\left(x_{2}\right)} \text {. }
$$

which due to CRRA implies

$$
x_{1}>\frac{1}{2} x_{2} .
$$

Autarky implies $x_{1}=\frac{1}{2} x_{2}$, so that this condition is met when smoothness of consumption is increased for all agents. Thus, the full set of IC constraints can be replaced by the local incentive constraints (28) and the requirement that $x_{1}>\frac{1}{2} x_{2}$.

The government's problem then is to solve

$$
\begin{aligned}
\max _{\left\{\tau_{1}, \tau_{2}\right\}} & \int_{\underline{\theta}}^{\bar{\theta}} u\left(\theta+\tau_{1}(\theta)\right)+u\left(2 \theta+\tau_{2}(\theta)\right) \\
\text { s.t. } & \int_{\Theta} \tau_{1}(\theta)+\tau_{2}(\theta) \leq 0 \\
& u^{\prime}\left(\theta+\tau_{1}(\theta)\right) \tau_{1}^{\prime}(\theta)+u^{\prime}\left(2 \theta+\tau_{2}(\theta)\right) \tau_{2}^{\prime}(\theta)=0 \quad \forall \theta .
\end{aligned}
$$

The first order conditions to this problem yield the following optimality condition:

$$
u^{\prime}\left(\theta+\tau_{1}(\theta)\right)-u^{\prime}\left(2 \theta+\tau_{2}(\theta)\right)=\gamma(\theta)\left(u^{\prime \prime}\left(\theta+\tau_{1}(\theta)\right) \tau_{1}^{\prime}(\theta)+u^{\prime \prime}\left(2 \theta+\tau_{2}(\theta)\right) \tau_{2}^{\prime}(\theta)\right) .
$$

where $\gamma(\theta)$ are the Lagrange multipliers on the incentive compatibility constraints. From this condition it follows that when $x_{1}(\theta)<x_{2}(\theta)$

$$
u^{\prime \prime}\left(\theta+\tau_{1}(\theta)\right) \tau_{1}^{\prime}(\theta)+u^{\prime \prime}\left(2 \theta+\tau_{2}(\theta)\right) \tau_{2}^{\prime}(\theta)<0 .
$$

CRRA implies that

$$
\frac{x_{2}}{x_{1}}=\frac{u^{\prime \prime}\left(x_{1}\right)}{u^{\prime \prime}\left(x_{2}\right)} \frac{u^{\prime}\left(x_{2}\right)}{u^{\prime}\left(x_{1}\right)}
$$

so that

$$
x_{1}(\theta)<x_{2}(\theta) \rightarrow \frac{x_{2}(\theta)}{x_{1}(\theta)}>\frac{u^{\prime}\left(x_{2}(\theta)\right)}{u^{\prime}\left(x_{1}(\theta)\right)} .
$$

Moreover, note that

$$
\frac{x_{2}(\theta)}{x_{1}(\theta)}=\frac{2 \theta+\tau_{2}(\theta)}{\theta+\tau_{1}(\theta)} \leftrightarrow \frac{x_{2}^{\prime}(\theta)}{x_{1}^{\prime}(\theta)}=\frac{2+\tau_{2}^{\prime}(\theta)}{1+\tau_{1}^{\prime}(\theta)} .
$$


We would like to show that the degree of smoothness as measured by the ratio $\frac{x_{1}}{x_{2}}$ is increasing in type, i.e

$$
\frac{\partial \frac{x_{1}(\theta)}{x_{2}(\theta)}}{\partial \theta}=\frac{x_{1}^{\prime}(\theta) x_{2}(\theta)-x_{1}(\theta) x_{2}^{\prime}(\theta)}{\left(x_{2}(\theta)\right)^{2}}>0 \leftrightarrow \frac{x_{2}(\theta)}{x_{1}(\theta)}>\frac{x_{2}^{\prime}(\theta)}{x_{1}^{\prime}(\theta)} .
$$

Combining optimality (35), CRRA (37), and (38) with (28) and (32) implies that (39) holds, and thus the degree of consumption smoothness increases with type. This concludes the proof.

\section{A.2 Proof of Lemma 3 - government without commitment}

First, suppose the information revelation rule was such that all information reported by the agents would be revealed to the government, i.e. $m(\theta)=\theta$ for all types $\theta$. Constraint (6) implies that if the government possesses any information about types at the beginning of the second period, it will exploit it so as to equalize consumption as much as possible. To see this, consider the first order conditions of the government's problem at $\mathrm{t}=2(6)$ :

$$
u^{\prime}\left(2 \theta+\tau_{2}^{\prime}(\theta)\right)-\lambda=0 \quad \forall \theta .
$$

These conditions imply that the government will choose $\left\{\tau_{2}^{\prime}\right\}$ so to equalize consumption across all agents, $x_{2}(\theta)=x_{2} \forall \theta$. From the agent's point of view then the consumption allocation in period 2 is fixed, and he solves:

$$
\max _{\hat{\theta}} u\left(x_{1}(\hat{\theta})+\theta-\hat{\theta}\right)+u\left(x_{2}+2(\theta-\hat{\theta})\right) .
$$

For truth-telling to be optimal, it is necessary for the first and second order conditions to be satisfied at $\hat{\theta}=\theta$, i.e. $\forall \theta$ :

$$
\begin{array}{r}
\left(x_{1}^{\prime}(\theta)-1\right) u^{\prime}\left(x_{1}(\theta)\right)-2 u^{\prime}\left(x_{2}\right)=0 \\
\left(x_{1}^{\prime}(\theta)-1\right)^{2} u^{\prime \prime}\left(x_{1}(\theta)\right)+x_{1}^{\prime \prime}(\theta) u^{\prime}\left(x_{1}(\theta)\right)+4 u^{\prime \prime}\left(x_{2}\right)<0 .
\end{array}
$$

Further differentiating (40) yields

$$
x_{1}^{\prime}(\theta)\left(x_{1}^{\prime}(\theta)-1\right) u^{\prime \prime}\left(x_{1}(\theta)\right)+x_{1}^{\prime \prime}(\theta) u^{\prime}\left(x_{1}(\theta)\right)=0,
$$

which reduces (41) to

$$
-\left(x_{1}^{\prime}(\theta)-1\right) u^{\prime \prime}\left(x_{1}(\theta)\right)+4 u^{\prime \prime}\left(x_{2}\right)<0 .
$$

This, together with (40) implies that for the allocation to be incentive compatible, it must be such that $\forall \theta$

$$
\begin{aligned}
-\frac{u^{\prime \prime}\left(x_{1}(\theta)\right)}{u^{\prime}\left(x_{1}(\theta)\right)} & <-2 \frac{u^{\prime \prime}\left(x_{2}\right)}{u^{\prime}\left(x_{2}\right)} \\
\leftrightarrow-\frac{u^{\prime \prime}\left(x_{1}(\theta)\right)}{u^{\prime}\left(x_{1}(\theta)\right)} x_{1}(\theta) x_{2} & <-2 \frac{u^{\prime \prime}\left(x_{2}\right)}{u^{\prime}\left(x_{2}\right)} x_{2} x_{1}(\theta) \\
\leftrightarrow x_{2} \frac{1}{\epsilon} & <2 x_{1}(\theta) \frac{1}{\epsilon},
\end{aligned}
$$


where $\epsilon$ is the elasticity of intertemporal substitution, which is constant by assumption. Thus, it must be true for all types that

$$
x_{1}(\theta)>\frac{1}{2} x_{2} .
$$

Moreover, (40) can be rearranged as

$$
x_{1}^{\prime}(\theta)=2 \frac{u^{\prime}\left(x_{2}\right)}{u^{\prime}\left(x_{1}(\theta)\right)}+1 .
$$

This differential equation determines the shape of the consumption schedule in period 1. Two properties are important: $x_{1}(\theta)$ is increasing in type, with a slope strictly larger than 1 , and with increasing slope. The lowest type, $\underline{\theta}$ will receive the lowest period 1 consumption. To relax incentive constraints for the higher types, it is optimal to start from the lowest possible $x_{1}(\underline{\theta})$. A lower bound is $x_{1}(\underline{\theta})=\frac{1}{2} x_{2}$. What is $x_{2}$ ?

$$
x_{2}=2 \int_{\underline{\theta}}^{\bar{\theta}} \theta d F(\theta)-\int_{\underline{\theta}}^{\bar{\theta}} x_{1}(\theta) d F(\theta)
$$

The second summand cannot be solved without further assumptions on the utility function. But we can use a conservative lower bound to see what the government would at most be able to achieve with a fully separating allocation. To that end, suppose we ignore that $x_{1}(\theta)$ has to be increasing with increasing slope, and rather assume that it will increase with constant slope $x_{1}^{\prime}(\underline{\theta}) \approx 2$. This is not a bad approximation, since constant elasticity of intertemporal substitution implies $u^{\prime \prime \prime}(\cdot)<0$ and so $\frac{u^{\prime}\left(x_{2}\right)}{u^{\prime}\left(\frac{1}{2} x_{2}\right)} \geq \frac{1}{2}$ is not a terrible assumption. This lower bound allows us to compute an upper bound on $x_{2}$ :

$$
\begin{array}{r}
x_{2} \leq 2 \int_{\underline{\theta}}^{\bar{\theta}} \theta d F(\theta)-\int_{\underline{\theta}}^{\bar{\theta}} \frac{1}{2} x_{2}+2(\theta-\underline{\theta}) d F(\theta) \\
\leftrightarrow x_{2} \leq \frac{4}{3} \underline{\theta} .
\end{array}
$$

This leaves the lowest type at best with the consumption allocation $\left[\frac{2}{3} \underline{\theta}, \frac{4}{3} \underline{\theta}\right]$. Notice that this means he is distributed away from in the aggregate and also does not gain any smoothness. This cannot be optimal from a social welfare point of view. It means that the only separating allocation that can be implemented is one that increases inequality and lowers welfare compared to autarky, and thus it is not optimal.

Notice that the argument does not change when the government learns only partial information about types. Since the second-period allocation is fixed, providing incentives for any separation through first-period transfers is so costly that it is not optimal to do so. Thus, the optimal information revelation rule is one where no information is revealed, i.e.

$$
m(\theta)=\underline{\theta} \quad \forall \theta
$$

This concludes the proof. 


\section{B Appendix: Remaining Proofs}

\section{B.1 Proof of Theorem 1}

This proof proceeds in two steps. First, I show that for any profile of messages resulting from an equilibrium strategy profile $\boldsymbol{\sigma}^{e}$ there exists another message profile that consists only of truthful messages but conveys the same information about the agents' types. Second, I show that for any pair of equilibrium strategies $\Gamma$ and $\boldsymbol{\sigma}$ that support an implementable mechanism, there exists another pair $\Gamma^{*}$ and $\boldsymbol{\sigma}^{*}$ which are best responses to each other and that induce a direct mechanism with the same payoffs and truth-telling.

Step 1: First note that it is without loss of generality to consider only deterministic strategies. Since there is no exogenous uncertainty in the model and agents have concave utility, the only reason they would consider randomizing messages would be in response to random tax assignments. However, due to the CRRA assumption, the government would not choose non-degenerate stochastic mechanisms (tax schedules). Since the objective function is concave, introducing risk could only improve matters if some incentive constraints were relaxed. Making payoffs for lower type agents riskier does indeed relax higher types' incentive constraints. However, since CRRA implies decreasing absolute risk aversion, the loss for the low types from facing such risk is always higher than the gain in terms of relaxing incentive constraints for higher types. See for example Fudenberg and Tirole (1991).

Let $\boldsymbol{z}_{\boldsymbol{\sigma}, \Gamma}$ denote the message profile resulting from strategy profile $\boldsymbol{\sigma}$ of the agents, given a strategy $\Gamma$ of the government. Then there exists a partition $\mathrm{M}$ of the type space $\Theta$, such that agents playing a truth-telling strategy and choosing one element $m \in M$ as their truthful message results in a message profile $\boldsymbol{z}^{*}$ such that there exists a one-to-one mapping between the message profiles. In other words, one can always construct a message space from which agents truthfully choose their report that reveals the exact same information to the planner. Since random messages have been ruled out, this is trivial to see. Any form of (partial) pooling that results from agents lying about their types can be replicated by partitioning the type space and using messages such as "at least type $\theta$ " or "between $\theta_{1}$ and $\theta_{2}$ ". Even messages with no content about the type whatsoever can be replaced by the truthful message "at least type $\underline{\theta} "$

Step 2: Now consider equilibrium strategies $\Gamma$ and $\boldsymbol{\sigma}$ that support an implementable mechanism $\tau$. Then by definition $\tilde{\tau}_{2}^{\prime}=\tau_{2}$, i.e. the government's best response to the information learned from the message profile $\boldsymbol{z}_{\boldsymbol{\sigma}, \Gamma}$ provides no incentive for it to deviate from the proposed tax schedule. Moreover, it must be true (by definition of an equilibrium) that the messages $z(\sigma(\theta, \gamma))$ resulting from the strategy profile $\boldsymbol{\sigma}$ and leading to the message profile $\boldsymbol{z}_{\sigma, \Gamma}$ are best responses to the mechanism $\tau$, so that:

$$
U(z((\theta)) \mid \theta, \boldsymbol{\sigma}, \Gamma) \geq U(\hat{z}((\theta) \mid \theta, \boldsymbol{\sigma}, \Gamma) \quad \forall z, \hat{z} \in Z
$$

Now consider the alternative strategy $\Gamma^{*}$ for the government that induces the action $\gamma=\left(\tau^{*}, \tau_{2}^{\prime}=\tau_{2}^{*}\right)$, where $\tau^{*}$ is a direct mechanism that maps from a message set $\tilde{M}$ 
to a set of tax and transfer payments, and where further $\tilde{M}$ is a partition of the type space $\Theta$ such that agents' truthful reporting would lead to a message profile $\boldsymbol{z}^{*}$ for which a one-to-one mapping to the message profile $\boldsymbol{z}_{\boldsymbol{\sigma}, \Gamma}$ exists. Moreover, suppose that the induced tax schedule $\tau^{*}$ assigns the same transfer payments, i.e

$$
\tau_{t}\left(z(\sigma(\theta, \gamma))=\tau_{t}^{*}\left(z^{*}(\theta)\right) \quad \forall \theta, t\right.
$$

Then, by construction, it must be true that

$$
\begin{aligned}
U\left(z^{*}(\theta) \mid \boldsymbol{\sigma}^{*}, \Gamma^{*}\right) & =U(z((\theta)) \mid \theta, \boldsymbol{\sigma}, \Gamma) \\
& \geq U(\hat{z}(\theta) \mid \theta, \boldsymbol{\sigma}, \Gamma) \\
& =U\left(z^{*}(\hat{\theta}) \mid \boldsymbol{\sigma}^{*}, \Gamma^{*}\right)
\end{aligned}
$$

for all $\theta, \hat{\theta} \in \Theta$. This implies that truth-telling is indeed a best response to $\Gamma^{*}$. Moreover, since the government payoff is unchanged, $\Gamma^{*}$ must also be a best response to $\boldsymbol{\sigma}^{*}$, thus establishing that the pair $\left(\Gamma^{*}, \boldsymbol{\sigma}^{*}\right)$ are an equilibrium.

\section{B.2 Proof of Proposition 1}

The proof of this proposition proceeds in two steps: First, I show that a fully revealing mechanism with separation in the second period is implementable if agents pledged their entire net income in financial contracts, $D>0$, and condition (21) is satisfied. Second, I show that agents pledging the entire net income in the second period is a best response to such a mechanism.

Step 1: Suppose agents signed gross contracts that pledge all their income in period 2, i.e.

$$
b_{2}(\theta)=y_{2}(\theta)+\tau_{2}(m(\theta))
$$

Suppose further that the government proposed a fully revealing mechanism, i.e. $m(\theta)=\theta$. Then, each agent's consumption in the second period is

$$
c_{2}(\theta)=h_{2}(m(\theta))
$$

i.e. agents planned to consume only what they arranged to receive from the bank.

For the mechanism $\tau$ to be implementable, it must be true that the government has no incentive to deviate from it in period 2 :

$$
\begin{aligned}
& \tau_{2} \in \arg \max _{\left.\tau_{2}^{\prime}\right\}} \int_{\Theta} \\
& \left.\tau_{2}^{\prime}\right\} \int_{\Theta}\left(h_{2}(m(\theta))\right) \quad \mathbb{I}\left\{y_{2}(\theta)+\tau_{2}^{\prime}(\theta) \geq b_{2}(\theta)\right\} \quad+ \\
& u\left(y_{2}(\theta)+\tau_{2}^{\prime}(\theta)-\left(d_{1}(\theta)+D\right)\right) \quad \mathbb{I}\left\{y_{2}(\theta)+\tau_{2}^{\prime}(\theta)<b_{2}(\theta)\right\} \quad d F(\theta) \\
& \text { s.t. } \int_{\Theta} \tau_{1}(\theta)+\tau_{2}^{\prime}(\theta) d F(\theta) \leq 0
\end{aligned}
$$


Since all agents have pledged their entire net income, every change in the promised tax schedule will lead to contracts being renegotiated and the default cost $D$ incurred. Therefore, this ex-interim problem can equivalently be expressed as the planner choosing a new consumption allocation $\left\{\hat{c}_{2}\right\}$ for the agents, taking the cost into account:

$$
\begin{aligned}
& \max _{\left\{\hat{c}_{2}(\theta)\right\}} \int_{\Theta} u\left(\hat{c}_{2}(\theta)\right) d F(\theta) \\
& \text { s.t. } \int_{\Theta} \hat{c}_{2}(\theta) d F(\theta) \leq \int_{\Theta}\left[h_{2}(\theta)-D \mathbb{I}\left\{\hat{c}_{2}(\theta)<h_{2}(\theta)\right\}\right] d F(\theta)
\end{aligned}
$$

This formulation nicely depicts the main point: The government is free to redistribute, but doing so is costly. The default $\operatorname{cost} D$ enters only on the resource side of the feasibility constraint. From here it is straightforward to note that:

\section{Lemma 5}

If there exists a solution to problem (53) such that $\left.\hat{c}_{2}(\theta) \neq h_{2}(\theta)\right)$ for at least one $\theta \in \Theta$, then it must be that $\left.\hat{c}_{2}(\bar{\theta})<h_{2}(\bar{\theta})\right)$.

Proof: Ex-ante incentive compatibility implies that the promised allocation in $t=2$ is at least weakly increasing in type, so that $\frac{\partial h_{2}(\theta)}{\partial \theta} \geq 0$. Thus, the gains from redistributing ex-post are highest when letting the highest type change his contract. The cost $D$, on the other hand, is fixed per head. Therefore, any optimal deviation from the promised allocation will distribute away from the highest type.

The lemma shows that a deviation from the promised tax schedule would always start at the top. Choosing the optimal deviation then becomes a problem of choosing the fraction of types at the top to distribute away from:

$$
\begin{gathered}
\max _{\epsilon}[F(\hat{\theta})+1-F(\bar{\theta})] u\left(h_{2}(\hat{\theta})\right)-\int_{\underline{\theta}}^{\hat{\theta}} u\left(h_{2}(\theta)\right) d F(\theta)-\int_{\bar{\theta}-\epsilon}^{\bar{\theta}} u\left(h_{2}(\theta)\right) d F(\theta) \\
\text { s.t. } h_{2}(\hat{\theta})=\frac{\int_{\underline{\theta}}^{\hat{\theta}} h_{2}(\theta) d F(\theta)+\int_{\bar{\theta}-\epsilon}^{\bar{\theta}}\left(h_{2}(\theta)-D\right) d F(\theta)}{F(\hat{\theta})+1-F(\bar{\theta})} \\
\quad \epsilon \geq 0
\end{gathered}
$$

The optimal $\epsilon$ maximizes the gain from distributing away from the top types $\theta \in$ $[\bar{\theta}-\epsilon, \bar{\theta}]$ toward the lowest types $\theta \in[\underline{\theta}, \hat{\theta}]$, where $\hat{\theta}$ is chosen to make optimal use of the resources gained at the top (i.e. is endogenous to the choice of $\epsilon$ ). The graph illustrates this choice: 


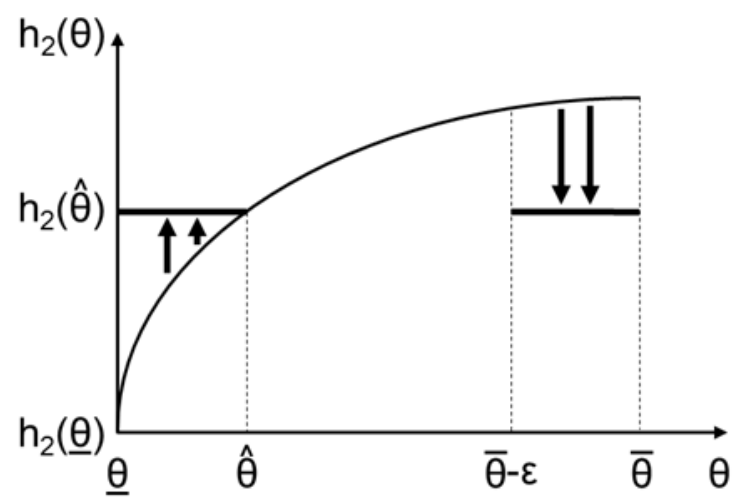

The promised mechanism is implementable, if the government would not even let the highest type default on his contract, i.e. if $\epsilon=0$ is optimal.

The first order condition to this problem, disregarding constraint (56) for the moment, is:

$$
f(\bar{\theta}-\epsilon) u\left(h_{2}(\hat{\theta})\right)+[F(\hat{\theta})+1-F(\bar{\theta}-\epsilon)] u^{\prime}(\hat{\theta}) \frac{\partial h_{2}(\hat{\theta})}{\partial \epsilon}-u\left(h_{2}(\bar{\theta}-\epsilon)\right) f(\bar{\theta}-\epsilon)=0
$$

where $f(\cdot)$ denotes the pdf of the type distribution $F(\cdot)$ and

$$
\begin{aligned}
\frac{\partial h_{2}(\hat{\theta})}{\partial \epsilon} & =\frac{\left(h_{2}(\bar{\theta}-\epsilon)-D\right)}{[F(\hat{\theta})+1-F(\bar{\theta}-\epsilon)]} \\
& -\left[\int_{\underline{\theta}}^{\hat{\theta}} h_{2}(\theta) d F(\theta)+\int_{\bar{\theta}-\epsilon}^{\bar{\theta}}\left(h_{2}(\theta)-D\right) d F(\theta)\right] \frac{f(\bar{\theta}-\epsilon)}{[F(\hat{\theta})+1-F(\bar{\theta}-\epsilon)]^{2}}
\end{aligned}
$$

Note that since $\hat{\theta}$ is chosen optimally depending on $\epsilon$, by the Envelope Theorem the derivative of $\hat{\theta}$ with respect to $\epsilon$ need not be taken into account. Further, note that

$$
\begin{aligned}
\int_{\underline{\theta}}^{\hat{\theta}} h_{2}(\theta) d F(\theta) & =F(\hat{\theta}) h_{2}(\hat{\theta})-\left[\int_{\bar{\theta}-\epsilon}^{\bar{\theta}}\left(h_{2}(\theta)-D\right) d F(\theta)-(1-F(\bar{\theta}-\epsilon)) h_{2}(\hat{\theta})\right] \\
& =[F(\hat{\theta})+1-F(\bar{\theta}-\epsilon)] h_{2}(\hat{\theta})-\int_{\bar{\theta}-\epsilon}^{\bar{\theta}}\left(h_{2}(\theta)-D\right) d F(\theta)
\end{aligned}
$$

so that the first order condition (57) simplifies to

$$
u^{\prime}\left(h_{2}(\hat{\theta})\right)\left(h_{2}(\bar{\theta}-\epsilon)-h_{2}(\hat{\theta})-D\right)+u\left(h_{2}(\hat{\theta})\right)-u\left(h_{2}(\bar{\theta}-\epsilon)\right)=0
$$

Thus, for $\epsilon=0$ to be optimal, condition (60) evaluated at 0 must be satisfied:

$$
u^{\prime}\left(h_{2}(\underline{\theta})\right)\left(h_{2}(\bar{\theta})-h_{2}(\underline{\theta})-D\right) \leq u\left(h_{2}(\bar{\theta})\right)-u\left(h_{2}(\underline{\theta})\right)
$$

It is a weak inequality instead of an equality, since the original problem also has the restriction (56). It is straight forward to show that the second order condition at 
$\epsilon=0$ is negative, so that (61) is a necessary and sufficient condition for optimality. This concludes the first step of the proof. It establishes that if all agents pledge their entire net income in the second period to the bank, then there exists a fully revealing mechanism that is implementable.

Step 2: It remains to be shown that signing a gross contract is indeed a best response to the mechanism. Since contracts are observable, it is obvious that any unpledged income will be taken away and redistributed. The cost $D$ that keeps the government from deviating from the promised tax schedule is only a threat when agents need to actually change their contracts. Thus, signing the required gross contracts is indeed a best response to any fully revealing and separating mechanism.

\section{B.3 Proof of Corollary 2}

The proof follows almost immediately from the proof of Proposition 1. The key is to notice that Lemma 5 includes situations when agents are pooled at the top. The lemma establishes that the government will always prefer to distribute away from the highest identified types first. This holds true, even if types are pooled at the top. Suppose agents above some cutoff $\tilde{\theta}$ are pooled together. Even if it is not optimal to let all of them default on their contracts, it might still be profitable for the government to default only on a fraction $\pi$ of them. The reason is that neither the gained resources nor the gain in welfare from redistributing these resources are are linear in $\pi$. The resources saved are optimally distributed toward the lowest types. Thus, the gain is the highest for the first redistributed dollars and decreases thereafter. The cost of changing contracts, however, is linear in the fraction $\pi$.

Suppose the government proposes a tax schedule that pools agents above a cutoff $\tilde{\theta}$ and fully separates them below, i.e. the information revelation rule of the mechanism is such that:

$$
\begin{array}{ll}
m(\theta)=\theta & \forall \theta \leq \tilde{\theta} \\
m(\theta)=\tilde{\theta} & \forall \theta>\tilde{\theta}
\end{array}
$$

Then choosing the optimal tax schedule that uses this form of restricted information and satisfies agents' incentive constraints to report their types according to this scheme is the following:

$$
\begin{gathered}
\max _{\pi}[F(\hat{\theta})+\pi(1-F(\tilde{\theta}))] u\left(h_{2}(\hat{\theta})\right)-\int_{\underline{\theta}}^{\hat{\theta}} u\left(h_{2}(\theta)\right) d F(\theta)-\pi(1-F(\tilde{\theta})) u\left(h_{2}(\tilde{\theta})\right) \\
\text { s.t. } h_{2}(\hat{\theta})=\frac{\left[\int_{\underline{\theta}}^{\hat{\theta}}\left(h_{2}(\theta)\right) d F(\theta)+\pi(1-F(\tilde{\theta}))\left(h_{2}(\tilde{\theta})-H\right)\right]}{(F(\hat{\theta})+\pi(1-F(\tilde{\theta})))} \\
0 \leq \pi \leq 1
\end{gathered}
$$


Following similar steps as in proof B.2 yields the analogous condition for the spread of consumption levels that the government knowingly can tolerate:

$$
u^{\prime}\left(c_{2}(\underline{\theta})\right)\left(c_{2}(\tilde{\theta})-c_{2}(\underline{\theta})-D\right)=u\left(c_{2}(\tilde{\theta})\right)-u\left(c_{2}(\underline{\theta})\right)
$$

\section{B.4 Proof of Corollary 3}

Following from Corollary 1, the ability to provide incentives for revelation achieved by $D>0$ is a weak improvement. However, under Assumption (A1) and with CRRA preferences, the government without commitment cannot implement any separation in types, so that with $D=0$ no social redistribution can be implemented. Then, the ability to achieve separation is a strict improvement. However, from Proposition 1 we know that the incentives that can be offered are constrained, so that the government might still not be able to achieve a full revelation. Yet, following from Corollary 2, the government is always able to implement a partially revealing allocation that pools agents at the top. Then, since the government was not able to achieve any redistribution otherwise, it will find it optimal to use this ability and implement at least a partially separating allocation. This constitutes a strict improvement over the case of $D=0$.

Moreover, it is straight forward to see that for any $D>0$, there exists a level of income inequality $\sum_{t=1}^{2}\left(y_{t}(\bar{\theta})-y_{t}(\underline{\theta})=3(\bar{\theta}-\underline{\theta})\right.$ between the lowest and highest type such that the ability to offer a differential consumption allocation that satisfies condition (21) of Proposition 1 is not enough to incentivize agents for full truthful revelation of their types. In that case, the best implementable mechanism must have a partially pooling information revelation rule, since only so can a welfare improvement be achieved. 